\title{
АНАЛИЗ НЕСУЩИХ СИСТЕМ СОВРЕМЕННЫХ ЛЕГКОВЫХ АВТОМОБИЛЕЙ
}

Голубина Светлана Александровна к.т.н., КФ МГТУ, РФ, г. Калуга

Карпов Максим Алексеевич Студент КФ МГТУ, РФ, г. Калуга Черенков Александр Григорьевич Студент КФ МГТУ, РФ , г. Калуга

\section{ANALYSIS OF LOAD-BEARING SYSTEMS OF MODERN PASSENGER CARS}

\author{
Candidate of Technical Sciences of the Kaluga branch of \\ the Moscow State Technical University named after N. Bauman, Russia, Kaluga \\ Karpov Maxim Alekseyevich \\ student of the Kaluga branch \\ of the Moscow State Technical University named after N. Bauman, Russia, Kaluga \\ Cherenkov Alexander Grigorievich \\ student of the Kaluga branch \\ of the Moscow State Technical University named after N. Bauman, Russia, Kaluga
}

Golubina Svetlana Aleksandrovna

Аннотация. В данной работе представлен сравнительный анализ несущих систем современных автомобилей. Рассмотрено устройство наиболее распространённых несущих систем легковых автомобилей, которые используются в настоящее время. Дано описание каждого типа и указана область их применения. На основании устройства каждого из описанных типов несущих систем выявлены как преимущества, так и недостатки данного типа. Исходя из проведенного анализа, выявлены основные тенденции развития данного направления.

Abstract. This paper presents a comparative analysis of the load-bearing systems of modern cars. The device of the most common load-bearing systems of passenger cars, which are currently used, is considered. Each type is described and the scope of their application is specified. Based on the device of each of the described types of carrier systems, both advantages and disadvantages of this type are identified. Based on the analysis, the main trends in the development of this direction are identified.

Ключевые слова: система, несущая система, лонжеронная рама, хребтовая рама, кузов, автомобиль.

Keywords: system, carrying system, spar frame, spinal frame, body, car.

Несущая система - является главным элементом любого транспортного средства. Все нагрузки, которые действуют на транспортное средство, воспринимаются несущей системой, она непосредственно влияет на технические характеристики автомобиля, а также на стоимость и безопасность. Несущая система автомобиля проектируется исходя из условий размещения всех его узлов, агрегатов и систем и соединения их в единую жесткую конструкцию. Современное производство стремится к увеличению жесткости несущей системы параллельно с минимизацией ее массы [5]. Однако для правильного решения данных задач, необходимо учитывать особенности конструкции отдельных типов несущих систем. В качестве несущей системы могут выступать рама или кузов автомобиля. Автомобильная рама выполняет функцию каркаса автомобиля, она придает жесткость и прочность всей конструкции, позволяя автомобилю воспринимать различные нагрузки при движении. Кузов автомобиля служит для размещения водителя, пассажиров, груза и защиты их от воздействия погодных условий, неблагоприятных факторов в движении, защиты при аварии.

В автомобилестроении используют несколько видов конструкций несущих систем [3]. Наиболее распространенные из них следующие:

- лонжеронная;

- лонжеронная переферийная;

- хребтовая;

- кузовная. 


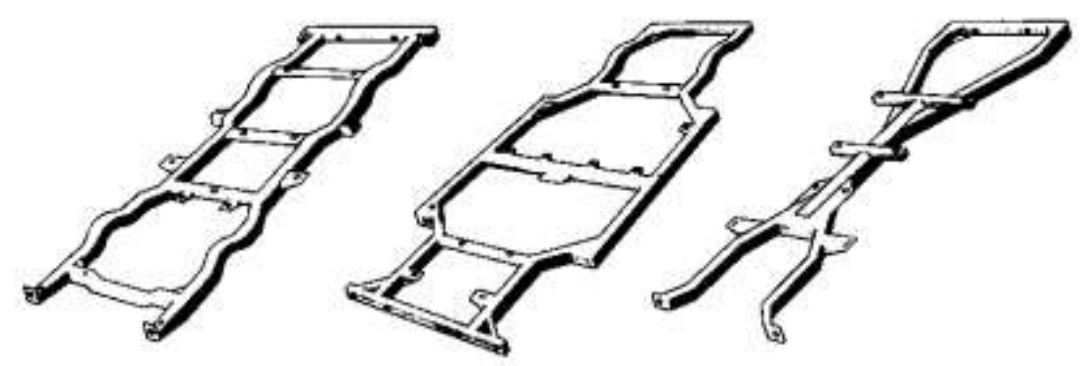

Рис. 1. Несущие системы автомобиля соответственно: лонжеронная, лонжеронная периферийная и хребтовая.

Лонжеронная рама - единая конструкция, которая изготовлена из пары лонжеронов, установленных продольно, и распорок, установленных поперечно. Чтобы создать подобную конструкцию применяют специальные швеллера с различной высотой сечения по всей длине лонжерона. В местах наибольшей нагрузки предусматривается максимальная высота конструкции [3]. Поперечины могут иметь различное исполнение. Бывают поперечины в форме букв «Х» и «К»; также могут иметь обычное и прямое устройство. С помощью кронштейнов обеспечивается монтаж механизмов и узлов агрегатов. Для фиксации разных рамных элементов применяют систему болтов, заклепочную технологию и полуавтоматическую сварку.

Периферийная рама - это разновидность лонжеронной рамы. Ее особенностью является особое изгибание во время изготовления. Это приводит к появлению в центральной части большего расстояния, что позволяет опускать все узлы и агрегаты автомобиля, снижать центр тяжести и увеличивать устойчивость на дороге.

Хребтовая рама - конструкция, в поперечном сечении которой лежит труба, которая объединяет силовой узел и основные узлы трансмиссии. Благодаря такой конструкции все основные детали машины становятся частью рамы. Все элементы закреплены жестко [2]. Момент вращения от мотора к трансмиссии передает вал, монтируемый внутри трубки. Применение такого варианта рамы возможно тогда, когда все колеса имеют независимую подвеску, транспортное средство используется на бездорожье или в особо тяжелых условиях. Недостатком такой конструкции является трудность ремонта и обслуживания. Чтобы обслужить какой-либо агрегат, нужно снять другие. Преимущества хребтовой рамы заключаются в простоте изготовления, простом создании машин с несколькими ведущими мостами, способности выдерживать огромные усилия на скручивание, высокая проходимость [6].

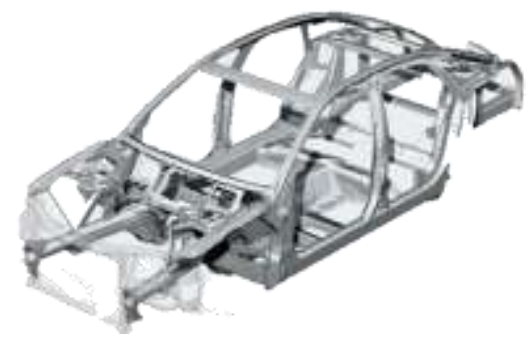

Рис. 2. Несущая система кузовного типа

Кузов - это несущая система автомобиля, на которую устанавливаются все узлы и агрегаты, а также принимает на себя все нагрузки и колебания, возникающие при эксплуатации [4].

Все кузова классифицируются по целому ряду признаков - по уровню нагрузки, комплектации, конструктивным особенностям и назначению. В легковых машинах обычно используется два типа кузовов пассажирские и грузопассажирские. По конструкции они бывают полу-каркасные и бескаркасные.

В зависимости от нагрузки транспортное средство может иметь несколько типов кузовов, таких как [1]:

- несущий - принимает всю массу и нагрузку на себя;

- полунесущий - отдает часть своей нагрузки раме;

- $\quad$ разгруженный - принимает на себя массу груза и людей в салоне.

В таблице 1 приведены характеристики, для сравнения достоинств и недостатков рассмотренных несущих систем.

Таблица 1

Характеристики рамной и кузовной конструкций

\begin{tabular}{|c|c|c|}
\hline & Рамная конструкция & Кузовная конструкция \\
\hline
\end{tabular}




\begin{tabular}{|c|c|c|}
\hline Несущая способность & Высокая & Средняя \\
\hline Сложность изготовления & Простая & Сложная \\
\hline Ремонтопригодность & Высокая & Визкая \\
\hline Износостойкость & Низкая & \\
\hline
\end{tabular}

Таким образом, исходя из проведенного анализа, можно сделать вывод, что в зависимости от условий эксплуатации и технико-экономических параметров наиболее целесообразно использовать инновационные конструкции автомобильных несущих систем. Благодаря правильному выбору системы можно в несколько раз повысить производитель автомобильной конструкции и уменьшить экономические затраты.

\section{Список литературы}

[1] Бадалов, В.В. Просто автомобиль. - 2-е изд., испр. и доп. - Санкт-Петербург : Издательство Политехнического университета, 2010. - 166 с.

[2] Волков В.С. Основы расчета систем автомобилей, обеспечивающих безопасность движения. - СПб: Издательство «Лань», 2015. - 144 с.

[3] Кащук, А.Н. Многоцелевые колесные машины : в 2 ч. - Екатеринбург : Издательство Уральского университета, 2013. - Ч. 2. Рама, трансмиссия и ходовая часть многоцелевых колесных машин. - 201 с.

[4] Костенко А.В., Петров А.В., Степанова Е.А. Автомобиль. Устройство. Автомобильные двигатели. Санкт-Петербург: Лань, 2020. - 436 с.

[5] Пачурин Г.В., Кудрявцев С.М., Соловьев Д.В., Наумов В.И. Кузов современного автомобиля: материалы, проектирование и производство. - СПб.: Издательство «Лань», 2018. - 316 с.

[6] Яковлев, Н.А. Автомобили и тракторы. - Москва ; Ленинград : Издательство Министерства коммунального хозяйства РСФСР, 1947. - 465 с. 